\title{
Individually Modified Saliva Delivery Changes the Perceived Intensity of Saltiness and Sourness
}

\author{
Cathrine Ingemarsdotter Heinzerling • \\ Markus Stieger • Johannes Hendrikus Fransiscus Bult • \\ Gerrit Smit
}

Received: 19 April 2011 / Accepted: 16 August 2011 /Published online: 3 September 2011

(C) The Author(s) 2011. This article is published with open access at Springerlink.com

\begin{abstract}
Individuals vary largely in their salivary flow and composition, and given the importance of saliva on perception of taste, this might influence how the tastant stimuli are perceived. We therefore hypothesise that altering the individual salivary flow rates has an impact on the perceived taste intensity. In this study, we investigated the role of saliva amount on the perceived taste intensity by excluding parotid saliva and adding artificial saliva close to the parotid duct at preset flow rates. Significant decreases in perception with increasing salivary flow rates were observed for citric acid and sodium chloride. This can partially be explained by a dilution effect which is in line with previous studies on detectable concentration differences. However, since the bitterness and sweetness remained unaffected by the salivary flow conditions and the dilution effect was comparable to that of saltiness, further explanation is needed. Furthermore, we investigated whether the suppression of taste intensity in binary mixtures (taste-taste interactions) could possibly be caused by the increased salivary flow rate induced by an additional
\end{abstract}

C. I. Heinzerling $\cdot$ M. Stieger $\cdot$ J. H. F. Bult

Top Institute Food and Nutrition (formerly WCFS),

PO Box 557, 6700 AN Wageningen, the Netherlands

C. I. Heinzerling $\cdot$ M. Stieger $\cdot$ G. Smit $(\bowtie)$

Agrotechnology and Food Sciences Group, Wageningen

University and Research Centre,

PO Box 8129, 6700 EV Wageningen, the Netherlands

e-mail: Gerrit.smit@wur.nl

J. H. F. Bult

NIZO Food Research B.V.,

PO Box 20, 6710 BA Ede, the Netherlands

G. Smit

Unilever R\&D Vlaardingen,

PO Box 114, 3130 AC Vlaardingen, the Netherlands taste attribute. The results show, however, that suppression of taste intensity in binary mixtures was not affected by the rate of salivation. This was more likely to be explained by psychophysics.

Keywords Dilution effect - Interactions · Salivation · Taste perception

\section{Introduction}

The role of saliva in food perception has been studied extensively (Bonnans and Noble 1995; Christensen et al. 1987; Delwiche and O'Mahony 1996; Engelen et al. 2003; Froehlich et al. 1987; Heinzerling et al. 2008; Lugaz et al. 2005; Matsuo 2000; Norris et al. 1984; Speirs 1971). Saliva from various salivary glands contributes to the bolus formation, of which the parotid glands contribute to more than half of the total salivary volume upon stimulation (Mese and Matsuo 2007; Pedersen et al. 2002; Shannon 1962; Van Nieuw Amerongen et al. 2004). The salivary flow secreted upon stimulation enables the transport of taste molecules to the taste bud (Matsuo 2000; Van Nieuw Amerongen et al. 2004). The composition of saliva is important for taste perception, i.e. the neutral $\mathrm{pH}$ of saliva along with its buffering action is of importance for the perception of sour stimuli (Christensen et al. 1987; Norris et al. 1984). Sodium salts present in saliva determine the level at which salt can be tasted in a product (Delwiche and O'Mahony 1996; Matsuo 2000; Spielman 1990). Furthermore, salivary enzymes start the process of digestion and can hereby influence the texture and taste perception by changing the viscosity of the food (Heinzerling et al. 2008). The amount of saliva secreted depends on the type and concentration of the taste stimuli perceived (Dawes and 
Watanabe 1987; Froehlich et al. 1987; Hodson and Linden 2006; Neyraud et al. 2009; Speirs 1971). In a previous study, we have shown that the composition of saliva depends more on the flow rate than on the type of stimulus. However, the protein concentration varies between different types of tastant stimuli, independent of the flow rate (Neyraud et al. 2009).

There is a large variation in salivary flow and composition between individuals (Heinzerling et al. 2008; Lugaz et al. 2005). Given the importance of saliva on taste perception, these inter-individual differences in salivation rate and composition may also influence how a stimulus is perceived. Norris et al. (1984) grouped subjects participating in a study according to their salivary flow rate and showed that subjects with a high flow rate had a higher taste threshold than subjects with a low flow rate. One possible explanation for this would be that a dilution of the stimulus occurs. We therefore hypothesise that altering the salivary flow rate has an impact on the perceived taste intensity. To test this hypothesis, we controlled the in vivo saliva release during consumption of various taste solutions by sealing off the parotid ducts with two Lashley cups. These Lashley cups allowed the collection of secreted saliva, preventing the saliva from being released into the mouth. Alternatively, artificial saliva was added back into the mouth of the subjects at well-controlled flow rates, allowing an intra-individual evaluation of taste intensities as a function of salivation rate. This method enabled an individually tuned delivery of artificial saliva at the location where saliva is normally secreted.

In addition, food products containing more than one taste modality are subject to taste-taste interactions (Keast and Breslin 2003; Pangborn 1960). This means that the perceived intensity of a taste attribute related to one tastant is influenced by the presence of another tastant. For instance, the sweetness of a given sucrose solution is generally suppressed by the addition of sour-tasting citric acid (Keast and Breslin 2003). Since different tastant solutions induce different salivation rates and altering the salivary flow rate might affect the perceived taste intensity, we hypothesise that taste-taste interactions are at least in part caused by an altered salivary flow rate. By comparing the perceived intensity of the binary solutions, under different saliva conditions, we could critically test this hypothesis.

\section{Materials and Methods}

Stimuli

The stimuli consisted of tastants dissolved in demineralised water (Table 1). Four basic tastes (sour, salt, bitter and
Table 1 Tastant stimuli and concentrations

\begin{tabular}{lll}
\hline Taste & Stimuli & Concentration $(\mathrm{mM})$ \\
\hline Sour & Citric acid & 7.9 \\
Salty & $\mathrm{NaCl}$ & 100 \\
Bitter & $\mathrm{MgSO}_{4}$ & 46 \\
Sweet & Sucrose & 100 \\
Sour + salty & Citric acid $+\mathrm{NaCl}$ & $7.9+100$ \\
Sour + sweet & Citric acid + sucrose & $7.9+100$ \\
\hline
\end{tabular}

sweet) were evaluated; two binary taste mixtures (sour/salty and sour/sweet) along with demineralised water served as a reference stimulus. The concentration of each stimulus was ten times stronger than the taste thresholds reported by Amerine et al. (1965).

\section{Subjects}

The tastant stimuli were evaluated by seven healthy

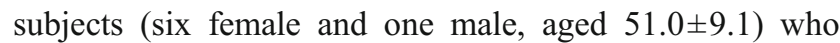
did not have any taste disorders and did not use medication that could affect taste, smell or salivary flow. All subjects gave written informed consent prior to the study.

\section{Salivary Flow}

Parotid saliva was collected using two modified Lashley cups placed over each parotid duct. The Lashley cup (Fig. 1) is a noninvasive method for collecting parotid saliva (Neyraud et al. 2009). The Lashley cup is fixed to the mucosa on the inside of the cheek by vacuum and the collected saliva flows out through a tube. In this study, the Lashley cups prevented the secretion of parotid saliva into the mouth. In addition, it was possible to measure the flow rate of the secreted saliva with a liquid mass flow meter directly connected to the outlet of the Lashley cup (ASL 1430-16, Sensirion, Stafa, Switzerland). An additional tube was fitted to the Lashley cup so that artificial saliva could

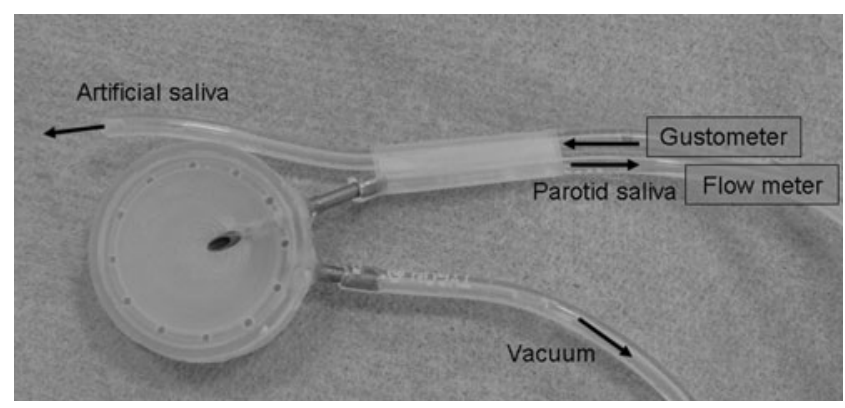

Fig. 1 Picture of the modified Lashley cup with the additional tube for delivery of artificial saliva into the mouth. The diameter of the disc is $22 \mathrm{~mm}$ 


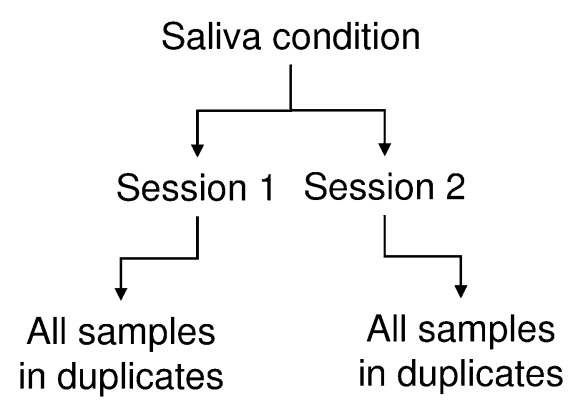

Fig. 2 Setup of experimental sessions

be delivered into the mouth at the same point as where the saliva would normally flow out.

\section{Artificial Saliva}

A buffered salt solution was used to mimic parotid saliva (Boland et al. 2004). The so-called artificial saliva consisted of: $\mathrm{NaHCO}_{3}(5.208 \mathrm{~g} / \mathrm{L}), \mathrm{K}_{2} \mathrm{HPO}_{4} \cdot 3 \mathrm{H}_{2} \mathrm{O}(1.369 \mathrm{~g} / \mathrm{L}), \mathrm{NaCl}$ $(0.877 \mathrm{~g} / \mathrm{L}), \mathrm{KCl}(0.447 \mathrm{~g} / \mathrm{L})$ and $\mathrm{CaCl}_{2} \cdot 2 \mathrm{H}_{2} \mathrm{O}(0.441 \mathrm{~g} / \mathrm{L})$. Mucins were not added to the artificial saliva since mucins are not present in the serous parotid saliva. Alpha-amylase was also not added to the artificial saliva since the tastant stimuli used were not expected to be affected by a starchhydrolysing enzyme.

\section{Measured Flow Rates and Saliva Conditions}

Based on the individually measured parotid salivary flow rates, different amounts of the artificial saliva were added into the mouths of the different subjects. The delivery of artificial saliva into the mouth of the subjects was controlled with a gustometer (Bult et al. 2007).

\section{Method}

The tastant stimuli $(10 \mathrm{~mL})$ were presented to the subjects in cups in random order. The subjects were instructed to take the stimulus into their mouth, hold it for $20 \mathrm{~s}$ and then spit it out. Thereafter, the perceived intensity of the tastant stimuli (sourness, saltiness, bitterness and sweetness) was scored by all subjects on a $10-\mathrm{cm}$ line scale, anchored 'not very intense' at the left end and 'very intense' at the right end.

During the whole session, two modified Lashley cups were positioned over the two parotid ducts of the subject. For each subject and each stimulus, the salivary flow was measured during the $20 \mathrm{~s}$ that the stimulus was kept in the mouth. From these measurements, the individual flow profiles were derived from which the delivery of the artificial saliva was defined. The subjects evaluated the tastant stimuli whilst artificial saliva was added into their mouth following their individual flow profiles. The artificial saliva was added according to three different saliva flow conditions. Each saliva flow condition was tested twice in separate sessions. In each session, all tastant stimuli were tested in duplicate (Fig. 2).

\section{Data Analysis}

The sampling frequency of the salivary flow rate was 1.6 Hz. The perceived intensity scores were normalized within each subject to obtain individual data sets with identical average $(M)$ and standard deviation (SD, Eq. 1):

normalized intensity $=\left(\left(\frac{\text { raw intensity }-M_{\text {subject }}}{\mathrm{SD}_{\text {subject }}}\right) \times \mathrm{SD}_{\text {group }}\right)+M_{\text {group }}$

The statistical analysis, ANOVA and post hoc comparison by Tukey HSD (SPSS, N17, Chicago, IL), was performed on the normalised perceived intensity and carried out separately for the four taste qualities (sourness, bitterness, saltiness and sweetness).

The first statistical analysis looked at the effect of the salivary flow conditions on the perceived intensity of each stimulus. The analysis was carried out for citric acid, magnesium sulphate, sodium chloride, sucrose, citric acid + sucrose and citric acid $+\mathrm{NaCl}$ independently to determine the effects of salivary flow conditions (fixed factor; main effect), replicate (fixed factor; main effect) and subject (random factor; main effect) on the perceived intensity; thus, no interaction effects were analysed. The betweensubject factors can be seen in Table 2; $N$ is not the same for all subjects due to missing values.
Table 2 Between-subject factors for the first statistical analysis

\begin{tabular}{llr}
\hline & & $N$ \\
\hline Condition & No flow & 25 \\
& Normal flow & 24 \\
& Increased flow & 28 \\
Replicate & 1 & 40 \\
Subject & 2 & 37 \\
& A & 12 \\
& B & 12 \\
& C & 10 \\
& D & 12 \\
& E & 9 \\
F & 10 \\
G & 12 \\
\hline
\end{tabular}


The second statistical analysis looked at the effect of the stimulus composition (taste-taste interactions) and whether this effect depends on the salivary flow conditions. The analysis was carried out for citric acid-containing stimuli (citric acid, citric acid + sucrose and citric acid $+\mathrm{NaCl}$ ), sucrose-containing stimuli (sucrose and citric acid + sucrose) and sodium chloride-containing stimuli $(\mathrm{NaCl}$ and citric acid $+\mathrm{NaCl}$ ). The effects of stimulus (fixed factor; main effect), subject and replicate (random factors; main effects) on perceived intensity were independently evaluated under each condition. Again, no interaction effects were analysed. The between-subject factors can be seen in Table 3; $N$ is not the same for all subjects due to missing values.
Table 3 Between-subject factors for the second statistical analysis

\begin{tabular}{|c|c|c|c|c|}
\hline & & \multicolumn{3}{|l|}{$N$} \\
\hline & & No flow & Normal flow & Increased flow \\
\hline \multicolumn{5}{|l|}{ Sourness } \\
\hline \multirow[t]{4}{*}{ Stimulus } & Water & 25 & 24 & 28 \\
\hline & Citric acid & 25 & 24 & 28 \\
\hline & Citric acid $+\mathrm{NaCl}$ & 25 & 24 & 27 \\
\hline & Citric acid + sucrose & 24 & 24 & 28 \\
\hline \multirow[t]{2}{*}{ Replicate } & 1 & 48 & 56 & 55 \\
\hline & 2 & 51 & 40 & 56 \\
\hline \multirow[t]{7}{*}{ Subject } & A & 16 & 16 & 16 \\
\hline & B & 16 & 16 & 16 \\
\hline & $\mathrm{C}$ & 16 & 8 & 16 \\
\hline & $\mathrm{D}$ & 16 & 16 & 16 \\
\hline & E & 4 & 16 & 15 \\
\hline & $\mathrm{F}$ & 16 & 8 & 16 \\
\hline & G & 15 & 16 & 16 \\
\hline \multicolumn{5}{|l|}{ Saltiness } \\
\hline \multirow[t]{3}{*}{ Stimulus } & Water & 25 & 24 & 28 \\
\hline & $\mathrm{NaCl}$ & 25 & 24 & 28 \\
\hline & Citric acid $+\mathrm{NaCl}$ & 25 & 24 & 27 \\
\hline \multirow[t]{2}{*}{ Replicate } & 1 & 36 & 42 & 41 \\
\hline & 2 & 39 & 30 & 42 \\
\hline \multirow[t]{7}{*}{ Subject } & A & 12 & 12 & 12 \\
\hline & B & 12 & 12 & 12 \\
\hline & $\mathrm{C}$ & 12 & 6 & 12 \\
\hline & $\mathrm{D}$ & 12 & 12 & 12 \\
\hline & E & 3 & 12 & 11 \\
\hline & $\mathrm{F}$ & 12 & 6 & 12 \\
\hline & G & 12 & 12 & 12 \\
\hline \multicolumn{5}{|l|}{ Sweetness } \\
\hline \multirow[t]{3}{*}{ Stimulus } & Water & 25 & 24 & 28 \\
\hline & Sucrose & 25 & 24 & 28 \\
\hline & Citric acid + sucrose & 24 & 24 & 28 \\
\hline \multirow[t]{2}{*}{ Replicate } & 1 & 36 & 42 & 42 \\
\hline & 2 & 38 & 30 & 42 \\
\hline \multirow[t]{7}{*}{ Subject } & A & 12 & 12 & 12 \\
\hline & $\mathrm{B}$ & 12 & 12 & 12 \\
\hline & $\mathrm{C}$ & 12 & 6 & 12 \\
\hline & $\mathrm{D}$ & 12 & 12 & 12 \\
\hline & E & 3 & 12 & 12 \\
\hline & $\mathrm{F}$ & 12 & 6 & 12 \\
\hline & G & 11 & 12 & 12 \\
\hline
\end{tabular}


Table 4 Description of the different saliva flow conditions

\begin{tabular}{ll}
\hline Condition & Description \\
\hline $\begin{array}{l}\text { 'No flow' } \\
\text { 'Normal flow' }\end{array}$ & $\begin{array}{l}\text { Artificial saliva corresponding to the normal flow } \\
\text { of each subject added }\end{array}$ \\
'Increased flow' & $\begin{array}{c}\text { Artificial saliva of which the average flow rate over } \\
\text { time equals the maximum flow for the subject. } \\
\text { This typically gives flow rates } 2 \text { times } \\
\text { the normal flow. }\end{array}$ \\
\end{tabular}

\section{Results}

\section{Dilution Effect of the Different Salivary Conditions}

$\mathrm{n}$ order to investigate the effect of saliva amounts on the perceived intensity, a methodology was developed which allowed the use of various salivary flow conditions. Three salivary flow conditions were defined. In the first condition, no artificial saliva was added. This means that since there was no parotid saliva entering the mouth and no artificial saliva, this was the 'no flow' condition. In the second flow condition, the artificial saliva was added according to the individual flow profiles for each person and stimulus, the 'normal flow'. In the third flow condition, an increased amount of artificial saliva was added, the 'increased flow' (Table 4).

This newly developed method makes it possible to modify the salivary flow specifically for each subject and for each specific stimulus. Because the artificial saliva was added into the mouth close to the parotid duct, it mimics how real parotid saliva normally enters the mouth. An overview of the individual flow rates and the dilution effects for the two different saliva flow conditions can be seen in Table 5. The dilution of the tastant was defined as the decrease in tastant concentration after the addition of artificial saliva, relative to its original concentration, and was calculated as follows (Eq. 2):

$$
\begin{aligned}
\text { dilution }= & \left(\frac{\left(\text { concentration }_{\text {in cup }}-\text { concentration }_{\text {in mouth }}\right)}{\text { concentration }_{\text {in cup }}}\right) \\
& \times 100
\end{aligned}
$$

This means that the dilution of the stimulus is measured and modulated per person in order to take into account as much as possible the individual differences in salivation.

As expected, citric acid stimulated the highest salivary flow rate, almost twice as much as that stimulated by magnesium sulphate, sodium chloride or sucrose (Table 5). Surprisingly, magnesium sulphate stimulated similar salivary amounts as sodium chloride and sucrose.

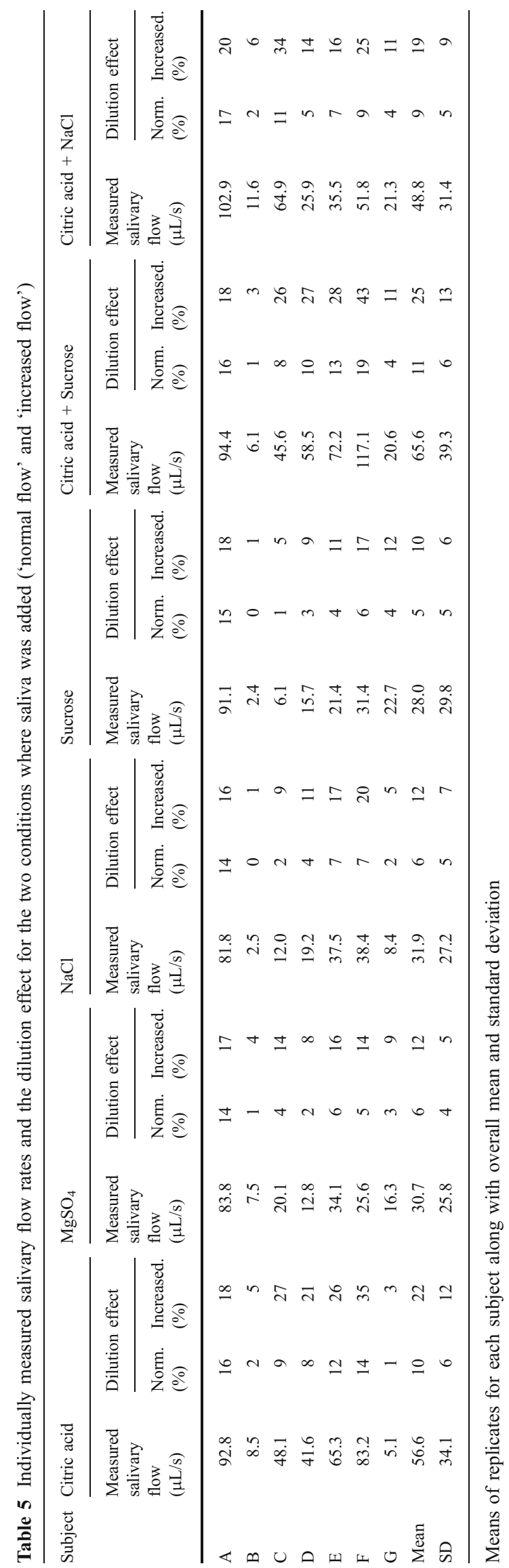


The difference in salivary flow between the single tastes and the binary mixtures was due to the presence of citric acid and was not influenced by the presence of another tastant. Citric acid-containing samples all stimulated a similar salivary flow rate.

Similar to what has been reported by others, we also saw large variations in salivary flow between individuals. For example, the measured salivary flow rate for citric acid ranges from 5 to $93 \mu \mathrm{L} / \mathrm{s}$. The advantage with our method was that it compensated for these individual differences.

Effect of Salivary Flow Conditions on the Perceived Intensity

The effect of the salivary flow conditions on the perceived intensity of the tastant stimuli can be seen in Fig. 3. There was a clear decrease in the perceived intensity of citric acid and sodium chloride with an increase of artificial salivary flow. For sucrose, there was a non-significant decrease in taste intensity with the presence of saliva ('normal flow' and 'increased flow') compared with the absence of saliva ('no flow'). The bitterness of magnesium sulphate was not affected by the salivary flow conditions.

The statistical analysis for citric acid showed a significant effect of salivary flow conditions $[F(2,67)=4.560, p=$ 0.014], but not of subject and replicate. The statistical analysis for sodium chloride showed a significant effect of both condition $[F(2,67)=5.930, p=0.004]$ and subject $[F(6$, $67)=9.498, p<0.001]$, but not for replicate. Neither magnesium sulphate nor sucrose was significantly affected by the salivary flow conditions or the replicate, and only magnesium sulphate showed a significant effect of subject $[F(6,67)=12.881, p<0.001]$.

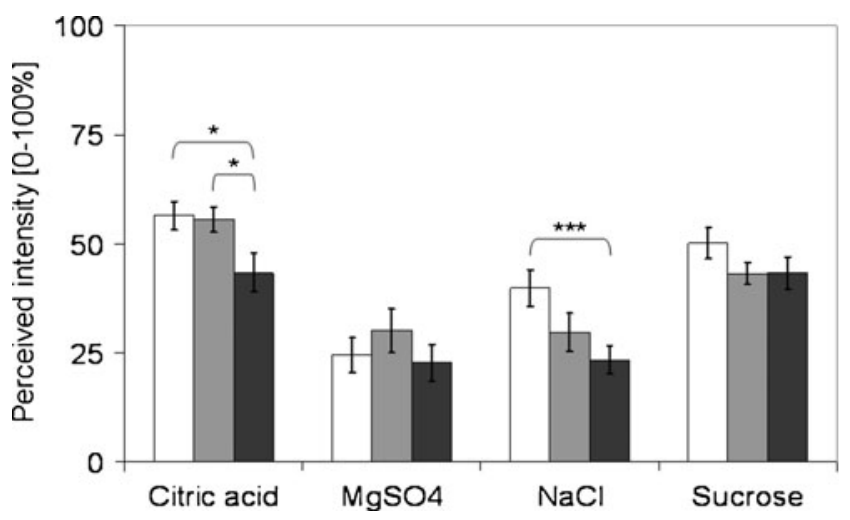

Fig. 3 Perceived intensity of citric acid, magnesium sulphate, sodium chloride and sucrose for the three salivary flow conditions: 'no flow' (white bars), 'normal flow' (grey bars) and 'increased flow' (black bars). The bars show the average of all assessors and replicates. Error bars equal the standard error of the mean. ${ }^{*} p<0.05, * * p<0.01, * * * p<0.001$

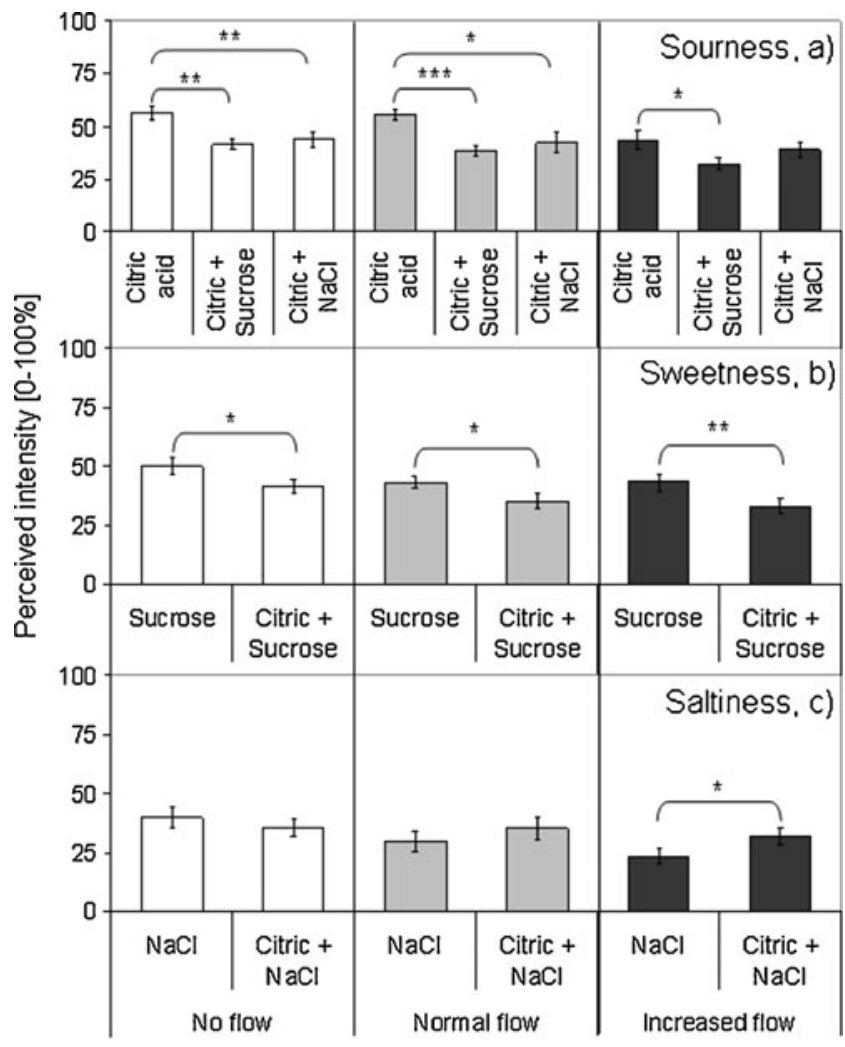

Fig. 4 Perceived sourness (a), sweetness (b) and saltiness (c) of basic tastes (citric acid, sucrose and sodium chloride) and binary mixtures of tastants (citric acid + sucrose and citric acid + sodium chloride) for the three saliva conditions: 'no flow' (white bars), 'normal flow' (grey bars) and 'increased flow' (black bars). The bars show the average of all assessors and replicates. Error bars equal the standard error of the mean. ${ }^{*} p<0.05, * * p<0.01, * * * p<0.001$

Influence of Saliva on Taste-Taste Interactions

The taste intensity of the binary solutions showed that taste-taste interactions occurred. For instance, the perceived sourness (Fig. 4a) was significantly higher for citric acid than for citric acid with sucrose or sodium chloride for the 'no flow' and 'normal flow' conditions. The same applied for the perceived sweetness which was significantly higher for sucrose than for citric acid with sucrose under all three flow conditions (Fig. 4b). However, for the perceived saltiness, no suppression could be seen when sodium chloride was tasted in combination with citric acid under the 'no flow' and 'normal flow' conditions (Fig. 4c).

Interestingly the observed taste-taste interactions (Fig. 4a, b) are not affected by the saliva since they occur both in the 'normal flow' (presence of saliva) and in the 'no flow' conditions (absence of saliva). Only the sweetness of sucrose with citric acid was significantly affected by the salivary flow conditions.

Statistical analysis showed that for sourness and sweetness, the effects of stimulus were independent of 
the salivary flow conditions (Fig. 4a, b): sourness-'no flow' $[F(3,88)=61.742, p<0.001]$, 'normal flow' $[F(3,85)=48.514, p<0.001]$ and 'increased flow' $[F(3,100)=45.524, p<0.001]$; sweetness-'no flow' $[F(2,64)=115.779, p<0.001]$, 'normal flow' $[F(2,62)=$ $95.008, p<0.001]$, and 'increased flow' $[F(2,74)=87.741$, $p<0.001]$. Saltiness only showed a significant effect for stimulus under the 'increased flow' condition (Fig. 4c) $[F(2,73)=41.124, p<0.001]$. The effect of salivary flow conditions on the different tastant mixtures only showed significant differences between the 'no flow' and 'increased flow' conditions for citric acid with sucrose $(p=0.035)$.

\section{Discussion}

Previous studies looking at the role of saliva on taste perception (Norris et al. 1984; Bonnans and Noble 1995; Lugaz et al. 2005) have compared different groups of people (healthy versus ill, old versus young, much saliva versus low amounts of saliva). Although these studies show the link between the amount of saliva and perception, comparisons between people merely suggest a relation between the two. Each person probably adapts to his own salivary flow rate. In a study by Engelen et al. (2003), different amounts of saliva were added to the stimulus. However, the saliva amounts added were the same for each individual. This implies that for an individual with a low flow, extreme amounts were added, and for a person with a high flow, the added amounts might have gone unnoticed. In our study, the artificial saliva was added at individually adjusted flow rates, allowing an intra-individual evaluation of taste intensities as a function of salivation rate.

Baek et al. (1999) described how sensory perception of volatiles is related to the rate of change of concentration. We hypothesised that taste perception, in a similar way, is related to temporal contrast. Salivation is continuous and therefore continuously decreases the concentration of the stimulus in the mouth. It can further be hypothesised that the location of this dilution is also of importance. Studying perception under spatial and temporal contrast is therefore an important difference between this and previous studies. In the study by Engelen et al. (2003), the dilution took place outside the mouth. In their study, the stimulus was presented on spoons and two fixed amounts of liquid (water, $\alpha$-amylase or saliva) were added directly to the spoon prior to digestion. They found none or only small effects on a number of taste and mouthfeel attributes.

The results from our study show that the perceived intensity of sourness and saltiness can be modified by a change in the salivary flow. However, the perception of sweetness and bitterness remained unaffected. It is known from studies by Laing et al. (1993) that the difference in concentration between two tastant stimuli has to be at least $13 \%$ to be perceived, with some marginal differences between the tastes (sucrose 14\%, sodium chloride $13 \%$ and citric acid 12\%). In our study, the difference in dilution, for citric acid, between the 'no flow' ( $0 \%)$, 'normal flow' $(10 \%)$ and 'increased flow' $(22 \%)$ conditions was above the detectable level as reported by Laing et al. (1993), and this could explain the significant perceivable difference. For sodium chloride, the difference in dilution between the 'no flow' condition $(0 \%)$ and the 'increased flow' condition (12\%) was just large enough to be perceived as different. For sucrose, however, the difference in dilution was just below the detectable level ( $5 \%$ 'normal flow' and $10 \%$ (increased flow'), and this could probably explain that no significant effects on the perceived intensity were found.

Although the dilution effect for sodium chloride was the same as for magnesium sulphate, the perception of the latter was not affected by the different saliva flow conditions. First of all, it was surprising that magnesium sulphate stimulated as much saliva as sodium chloride. In previous studies (unpublished results), magnesium sulphate hardly stimulated any saliva at all. Secondly, it is possible that the perceivable difference in concentration is higher for magnesium sulphate than for sodium chloride and that we therefore see an effect of dilution on sodium chloride, but not magnesium sulphate.

Other explanations might be found in the composition of the saliva. Saliva is known to influence the perception of acids and salts due to its buffering action and salt content (Behrens and Meyerhof 2006). Furthermore, the different tastes stimulate different taste receptors. Both citric acid and sodium chloride, which were both significantly affected by the salivary flow conditions, activate ion channel receptors. It is possible that the ion channel receptor is more sensitive to the ion composition of saliva and that this might explain our findings.

Taste-taste interactions were observed in our study, but were found to be independent from the salivary flow conditions. If taste-taste interactions depended on an increased amount of saliva (resulting from more taste attributes being present), they would not occur under the 'no flow' condition. However, this was the case for both sourness and sweetness. There was no suppression of saltiness under the 'no flow' condition, but also not under the 'normal flow' condition.

The suppression of sourness and sweetness in the presence of more than one taste attribute under the 
'normal flow' and 'increased flow' conditions can also not be explained by the dilution. The difference in dilution is too low to be perceived. The difference in dilution between the sucrose-containing stimuli might only have been noticable for the 'increased flow' condition (sucrose, 10\%; sucrose + citric acid, 25\%). Thus, the taste-taste interactions are not likely to be due to the additional amounts of saliva induced by the combination of two taste attributes. It is more likely to be caused by other factors, for example competition at the receptor level or cross-modal interactions. We may conclude from this that taste-taste interactions are not explained by additional saliva dilution of the tastant stimuli.

Our study showed that it is possible to modify the perceived sourness and saltiness by increasing the individual salivary flow rate. Furthermore, taste-taste interactions are not explained by the amount of induced saliva since they also occur when no saliva is present. Putting all the results together, saliva is necessary to transport taste molecules to the taste receptor. In case the saliva volume is strongly diminished due to illness, medication or old age, taste molecules might have difficulties reaching the taste receptors. This reduction in salivary flow can result in a reduced taste perception (Spielman 1990). Norris et al. (1984) on the other hand described how (healthy) subjects with a high flow also had a higher taste threshold, meaning that 'too much' saliva also has a taste-reducing effect. It is clear that there is an optimum amount of saliva in relation to taste perception and that this optimum is individual.

\section{Conclusions}

The manuscript presents a new method to individually modify in-mouth saliva delivery to determine the effect of salivation on taste perception. We hypothesised that an altered salivary flow rate has an impact on the perceived intensity. This is true for the perceived sourness and saltiness, but not for the perceived bitterness and sweetness. The second hypothesis, stating that taste-taste interactions are partly caused by an additional amount of saliva, was not confirmed in this study. Taste-taste interactions are likely to be due to other factors.

Acknowledgements Thanks are expressed to Dr. S. Körkel for his help and support with the statistical analysis, to Dr. H.H.J. de Jongh whose valuable comments helped complete this manuscript, and to $\mathrm{M}$. Smiddy for proof reading the manuscript. This work was supported by the European Commission (DiOGenes, http://www.diogenes-eu.org; FP6-FOOD-CT-2005-513946)
Open Access This article is distributed under the terms of the Creative Commons Attribution Noncommercial License which permits any noncommercial use, distribution, and reproduction in any medium, provided the original author(s) and source are credited.

\section{References}

Amerine MA, Pangborn RM, Roessler EB (1965) Principles of sensory evaluation of food. Academic, New York

Baek I, Linforth RST, Blake A, Taylor AJ (1999) Sensory perception is related to the rate of change of volatile concentration in-nose during eating of model gels. Chem Senses 24:155-160

Behrens M, Meyerhof W (2006) Bitter taste receptors and human bitter taste perception. Cell Mol Life Sci 63:1501-1509

Boland AB, Buhr K, Giannouli P, van Ruth SM (2004) Influence of gelatin, starch, pectin and artificial saliva on the release of 11 flavour compounds from model gel systems. Food Chem $86: 401-411$

Bonnans SR, Noble AC (1995) Interaction of salivary flow with temporal perception of sweetness, sourness, and fruitiness. Physiol Behav 57:569-574

Bult JHF, De Wijk RA, Hummel T (2007) Investigations on multimodal sensory integration: texture, taste, and ortho- and retronasal olfactory stimuli in concert. Neurosci Lett 411:6-10

Christensen CM, Brand JG, Malamud D (1987) Salivary changes in solution $\mathrm{pH}-\mathrm{a}$ source of individual-differences in sour taste perception. Physiol Behav 40:221-227

Dawes C, Watanabe S (1987) The effect of taste adaptation on salivary flow-rate and salivary sugar clearance. J Dent Res 66:740-744

Delwiche J, O’Mahony M (1996) Changes in secreted salivary sodium are sufficient to alter salt taste sensitivity: use of signal detection measures with continuous monitoring of the oral environment. Physiol Behav 59:605-611

Engelen L, de Wijk RA, Prinz JF, Janssen AM, van der Bilt A, Weenen H, Bosman F (2003) A comparison of the effects of added saliva, alpha-amylase and water on texture perception in semisolids. Physiol Behav 78:805-811

Froehlich DA, Pangborn RM, Whitaker JR (1987) The effect of oralstimulation on human-parotid salivary flow-rate and alphaamylase secretion. Physiol Behav 41:209-217

Heinzerling CI, Smit G, Dransfield E (2008) Modelling oral conditions and thickness perception of a starch product. Int Dairy J 18:867-873

Hodson NA, Linden RWA (2006) The effect of monosodium glutamate on parotid salivary flow in comparison to the response to representatives of the other four basic tastes. Physiol Behav 89:711-717

Keast SJR, Breslin PAS (2003) An overview of binary taste-taste interactions. Food Qual Preference 14:111-124

Laing DG, Prescott J, Bell GA, Gillmore R, James C, Best DJ, Allen S, Yoshida M, Yamazaki K (1993) A cross-cultural study of taste discrimination with Australians and Japanese. Chem Senses 18:161-168

Lugaz O, Pillias AM, Boireau-Ducept N, Faurion A (2005) Timeintensity evaluation of acid taste in subjects with saliva high flow and low flow rates for acids of various chemical properties. Chem Senses 30:89-103

Matsuo R (2000) Role of saliva in the maintenance of taste sensitivity. Crit Rev Oral Biol Med 11:216-229

Mese H, Matsuo R (2007) Salivary secretion, taste and hyposalivation. J Oral Rehabil 34:711-723 
Neyraud E, Heinzerling CI, Bult JHF, Mesmin C, Dransfield E (2009) Effects of different tastants of parotid saliva flow and composition. Chemosens Percept 2:108-116

Norris MB, Noble AC, Pangborn RM (1984) Human-saliva and taste responses to acids varying in anions, titratable acidity, and $\mathrm{pH}$. Physiol Behav 32:237-244

Pangborn RM (1960) Taste interrelationships. J Food Sci 25:245-256

Pedersen AM, Bardow A, Jensen SB, Nauntofte B (2002) Saliva and gastrointestinal functions of taste, mastication, swallowing and digestion. Oral Dis 8:117-129
Shannon IL (1962) Parotid fluid flow rate as related to whole saliva volume. Arch Oral Biol 7:391-394

Speirs RL (1971) The effects of interactions between gustatory stimuli on the reflex flow-rate of human parotid saliva. Arch Oral Biol $16: 351-365$

Spielman AI (1990) Interaction of saliva and taste. J Dent Res 69:838-843

Van Nieuw Amerongen AA, Veerman ECI, Vissink A (2004) Speeksel, speekselklieren en mondgezondheid. Bohn Stafleu Van Loghum, Houten 